\title{
Stabilization of fish oil-loaded electrosprayed capsules with seaweed and commercial natural antioxidants: effect on the oxidative stability of capsule-enriched mayonnaise
}

\author{
Hermund, Ditte Baun; Jacobsen, Charlotte; Chronakis, loannis S.; Pelayo, Andres; Yu, Sen; Busolo, \\ María; Lagaron, Jose M.; Jónsdóttir, Rosa; Kristinsson, Hordur G.; Akoh, Casimir C.
}

Total number of authors:

11

Published in:

European Journal of Lipid Science and Technology

Link to article, DOI:

10.1002/ejlt.201800396

Publication date:

2019

Document Version

Peer reviewed version

Link back to DTU Orbit

Citation (APA):

Hermund, D. B., Jacobsen, C., Chronakis, I. S., Pelayo, A., Yu, S., Busolo, M., Lagaron, J. M., Jónsdóttir, R., Kristinsson, H. G., Akoh, C. C., \& García Moreno, P. J. (2019). Stabilization of fish oil-loaded electrosprayed capsules with seaweed and commercial natural antioxidants: effect on the oxidative stability of capsule-enriched mayonnaise. European Journal of Lipid Science and Technology, 121(4), [1800396]. https://doi.org/10.1002/ejlt.201800396

\section{General rights}

Copyright and moral rights for the publications made accessible in the public portal are retained by the authors and/or other copyright owners and it is a condition of accessing publications that users recognise and abide by the legal requirements associated with these rights.

- Users may download and print one copy of any publication from the public portal for the purpose of private study or research.

- You may not further distribute the material or use it for any profit-making activity or commercial gain

- You may freely distribute the URL identifying the publication in the public portal 


\section{Research Article}

Stabilization of fish oil-loaded electrosprayed capsules with seaweed and commercial natural antioxidants: effect on the oxidative stability of capsule-enriched mayonnaise ${ }^{\dagger}$

Running title: Antioxidants effect on omega-3 nano-microcapsules

Ditte Hermund $^{\mathrm{a}}$, Charlotte Jacobsen ${ }^{\mathrm{a}}$, Ioannis S. Chronakis ${ }^{\mathrm{a}}$, Andres Pelayo ${ }^{\mathrm{a}}$, Sen Yu ${ }^{\mathrm{a}}$, María

Busolo $^{\text {b,c }}$, Jose M. Lagaron ${ }^{\mathrm{b}}$, Rosa Jónsdóttir ${ }^{\mathrm{d}}$, Hordur G. Kristinsson ${ }^{\mathrm{d}}$, Casimir C. Akoh ${ }^{\mathrm{a}, \mathrm{e}}$, Pedro J.

García-Moreno $^{\mathrm{a}}$

${ }^{a}$ Division of Food Technology, National Food Institute, Technical University of Denmark, Denmark

${ }^{\mathrm{b}}$ Novel Materials and Nanotechnology Group, IATA-CSIC, Spain

${ }^{\mathrm{c}}$ Bioinicia S.L., Spain

¿ Matís, Iceland

e Department of Food Science and Technology, University of Georgia, USA

Correspondence: Pedro J. García-Moreno. Division of Food Technology, National Food Institute, Technical University of Denmark, Denmark. E-mail: pejeg@food.dtu.dk

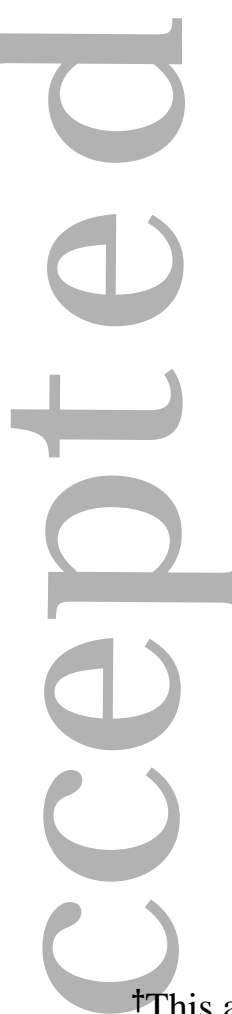

†This article has been accepted for publication and undergone full peer review but has not been through the copyediting, typesetting, pagination and proofreading process, which may lead to differences between this version and the Version of Record. Please cite this article as doi: [10.1002/ejlt.201800396]

(c) 2019 WILEY-VCH Verlag GmbH \& Co. KGaA, Weinheim

Received: September 19, 2018 / Revised: December 21, 2018 / Accepted: January 28, 2019 
Abstract

This study investigated the stabilization of fish oil-loaded electrosprayed capsules with different natural antioxidants: i) an ethanol extract from the brown alga Fucus vesiculosus, or ii) a combination of $\delta$ tocopherol and rosemary extract. The seaweed extract enhanced the oxidative stability of fish oil-loaded capsules with dextran as the main biopolymer wall material, but showed a prooxidant effect in fish oilloaded capsules having glucose syrup as the main biopolymer. These results can mainly be explained by the higher encapsulation efficiency of dextran capsules when compared to glucose capsules (90 vs. 83-85 \%), which prevented interaction of metal ions present in the extract with non-encapsulated oil. On the contrary, the addition of a lipophilic radical scavenger such as $\delta$-tocopherol in combination with synergistic antioxidants such as carnosic acid and carnosol present in rosemary extract improved the oxidative stability of glucose syrup capsules during 21 day storage, but not when the capsules were added to mayonnaise. Moreover, the capsule-containing mayonnaise presented a larger droplet size and higher apparent viscosity than mayonnaise enriched with neat fish oil. Both findings indicate that the structure of capsules may have been lost when added to a water-based food matrix (e.g. mayonnaise) and this requires further investigation.

\section{Practical applications}

Novel omega-3 delivery systems that are more easily dispersed and still maintain their oxidative stability are needed by the food industry. Electrosprayed capsules with a reduced size when compared to spraydried capsules, and which are produced without the need of heat for drying emulsions are promising omega-3 powdered encapsulates. Moreover, the addition of natural antioxidants, commonly used by the industry to further stabilize omega-3 encapsulates, deserves scientific attention. This study reveals the effect of seaweed antioxidants (e.g. phlorotannins) and commercial natural antioxidants (e.g. $\delta$ tocopherol and rosemary extract) on the oxidative stability of electrosprayed capsules loaded with fish oil. In addition, the effect of adding the capsules to a food matrix such as mayonnaise has been 
investigated. Although further development is necessary, these results will open up new strategies to enrich food products with omega-3 polyunsaturated fatty acids.

Keywords: Omega-3; Encapsulation; Electrospraying; Seaweed; Antioxidants; Mayonnaise

\section{Introduction}

Long chain polyunsaturated omega-3 fatty acids (omega-3 PUFAs) such as eicosapentaenoic (EPA, C20:5n-3) and docosahexaenoic (DHA, C22:6n-3) acids present several benefits on human health [1]. Therefore, the food industry is producing omega-3 fortified food products such as mayonnaise, milk, bread and others [2]. Nevertheless, these omega-3 PUFA are highly susceptible to oxidation [3], and enrichment of food products with neat fish oil (which is rich in EPA and DHA) decreases their oxidative stability [4].

Encapsulation of fish oil by electrospraying is a promising approach to protect the long chain omega-3PUFAs from oxidation [5]. Electrospraying uses high voltage to break up a jet of biopolymer solution containing fish oil to small droplets from where the solvent (e.g. water) is evaporated at room temperature. Thus, this technology, which does not require the employment of heat is highly beneficial for the encapsulation of temperature-sensitive lipids such as omega-3 PUFAs [6]. However, due to the high specific surface area of the encapsulates and to the several operations (e.g. emulsification and drying) involved in the process where prooxidants (e.g. light, oxygen) are not totally avoided, it might be necessary to have further control of oxidation to prevent deteriorative quality changes in the capsules. This can be done by addition of antioxidants as previously shown for the stabilization of electrospun fibers loaded with fish oil [7]. Although, synthetic antioxidants such as butylated hydroxytolulene (BHT) and ethylenediaminetetraacetic acid (EDTA), are extensively used to hinder lipid oxidation in foods, some restrictions have been made on their application in food due to possible toxicity and health issues [8]. Moreover, most of antioxidants usually have a single antioxidant property, like metal chelating ability or radical scavenging activity, which in many cases makes them inefficient to prevent oxidative flavour deterioration in fish oil enriched foods. Hence, combinations of antioxidants exhibiting different antioxidant properties are commonly employed [9]. In addition, and due to the consumers' 
increasing demand for clean labelling and sustainable ingredients, there is an emerging interest to find natural plant-based antioxidants with multiple antioxidant properties [10].

Brown alga Fucus vesiculosus is rich in phlorotannins, a major polyphenolic group which consists of up to eight interconnected rings (phloroglucinol units) [11], [12]. This structure makes phlorotannins more antioxidative than monophenols and some polyphenols containing less phenolic rings and therefore also fewer functional -OH groups [13]. Hermund et al. [14] and Honold et al. [15] found that different extracts of Icelandic $F$. vesiculosus showed not only excellent in vitro antioxidant properties (e.g. radical scavenging activity and metal chelating ability) but also a great potential as natural antioxidants in emulsified foods such as milk and mayonnaise enriched with fish oil. Moreover, the antioxidant efficacy of ethanol extract from $F$. vesiculosus has also been confirmed in granola bars enriched with fish oil-in-water emulsions [16].

In the light of the above, this study aimed at investigating the stabilization of electrosprayed capsules loaded with fish oil by using an ethanol extract from the brown alga $F$. vesiculosus. The antioxidant activity of the extract was evaluated during storage of the electrosprayed capsules and its effect was compared to the addition of other commercial natural antioxidants such as $\delta$-tocopherol and rosemary extract. Finally, light-mayonnaise was enriched with selected electrosprayed capsules and its physical and oxidative stabilities were determined during 28 day storage.

\section{Materials and Methods}

\subsection{Materials}

Dextran (molecular weight $=70 \mathrm{kDa}$ ) was generously provided by Pharmacosmos A/S (Holbaek, Denmark). Glucose syrup (DE38, C*Dry 1934) was donated by Cargill Germany GmbH (Krefeld, Germany). Pullulan (molecular weight $=200 \mathrm{kDa}$ ) was kindly provided by Hayashibara Co., Ltd. (Okayama, Japan). Whey protein concentrate (WPC), under the commercial name of Lacprodan® DI8090, was provided by ARLA Food Ingredients (Viby, Denmark). Citrem (citric acid ester without antioxidants) was provided by Danisco (Copenhagen, Denmark). The peroxide value (PV) of the citrem used was $2.3 \pm 0.1 \mathrm{meq} / \mathrm{kg}$ oil. Commercial cod liver oil was donated by Maritex A/S, subsidiary of 
TINE, BA (Sortland, Norway) and stored at $-40{ }^{\circ} \mathrm{C}$ until use. The major fatty acid composition of the fish oil was: C16:0, 9.5\%; C16:1, 8.7\%; C18:1, 16.3\%; C20:1, 12.6\%; C20:5, 9.2\% and C22:6, 11.4\%.

The tocopherol content of the fish oil was: $\alpha$-tocopherol, $200 \pm 3 \mu \mathrm{g} / \mathrm{g}$ oil; $\beta$-tocopherol, $5 \pm 1 \mu \mathrm{g} / \mathrm{g}$ oil; $\gamma$ tocopherol, $96 \pm 3 \mu \mathrm{g} / \mathrm{g}$ oil and $\delta$-tocopherol, $47 \pm 1 \mu \mathrm{g} / \mathrm{g}$ oil. PV of the fish oil used was $0.4 \pm 0.1 \mathrm{meq} / \mathrm{kg}$

oil. The rapeseed oil use in the production of the mayonnaise was kindly donated by AAK Sweden AB

(Karlshamn, Sweden). The major fatty acids of the rapeseed oil were: C16:0, 4.4\%; C18:1, 58.3\%; C18:2, 18.9\%; and C18:3, 9.3\%. This oil had a PV of $0.2 \pm 0.0 \mathrm{meq} / \mathrm{kg}$ oil and a tocopherol content of $193 \pm 1 \mu \mathrm{g} \alpha$-tocopherol/g oil and 96 $\pm 3 \mu \mathrm{g} \gamma$-tocopherol/g oil. The properties of the oils and emulsifiers used were determined as described elsewhere [5, 7].

Seaweed antioxidants were obtained after ethanolic extraction of $F$. vesiculosus and their properties characterized as described elsewhere $[15,16]$. The composition of potential antioxidant or prooxidant compounds in the ethanol extract was as follows: total phenolic content (g of gallic acid equivalent/ 100

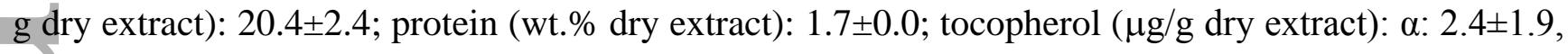
ß: $1.7 \pm 0.3, \gamma: 1.8 \pm 0.5, \delta: 18.0 \pm 4.4$; iron ( $\mu \mathrm{g} / \mathrm{g}$ dry extract): $14.5 \pm 0.1$; and pigments ( $\mu \mathrm{g} / \mathrm{mg}$ dry extract): chlorophylls: $2.0 \pm 0.2$, carotenoids: $7.6 \pm 0.9$. Antioxidant properties (at a concentration of $1.5 \mathrm{mg}$ dry extract/mL water) of the seaweed extract were as follows: DPPH radical scavenging activity (\%):

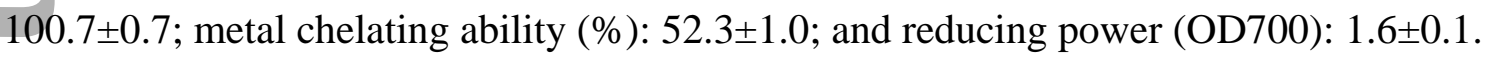

Water dispersible rosemary extract containing $1.5 \%$ carnosic acid and $0.4 \%$ carnosol was kindly provided by Kalsec ${ }^{\circledR}$ (Denver City, Texas, United States). $\delta$-Tocopherol was purchased from Sigma Aldrich (Brøndby, Denmark). Potassium sorbate was purchased from Merck (Darmstadt, Germany). Stabilizer Grindsted FF was purchased from Danisco (Copenhagen, Denmark). Egg yolk, salt, vinegar and sugar were purchased from the local supermarket. All other chemicals and solvents used were of analytical grade.

\subsection{Production of biopolymer solutions containing fish oil and antioxidants}

First, WPC (0.5 wt.\%), citrem (0.5 wt.\%) and i) pullulan (1 wt.\%) and dextran (15 wt.\%), or ii) pullulan (4 wt.\%) and glucose syrup (15 wt.\%) were dissolved in distilled water by stirring overnight at $500 \mathrm{rpm}$. 
These biopolymer concentrations were optimized in our previous study for the production of electrosprayed capsules with dextran or glucose syrup as main wall materials [17]. Then, antioxidants were added: a) $1 \mathrm{~g}$ of seaweed extract per $70 \mathrm{~g}$ oil (this concentration was selected based on our previous study on granola bars, [18]), or b) commercial antioxidants: $500 \mathrm{ppm}$ of $\delta$-tocopherol and $500 \mathrm{ppm}$ of rosemary extract (these concentrations were selected based on our previous work on pullulan electrospun fibers, [7]). Commercial antioxidants were added only to the glucose syrup solution due to a large availability of this biopolymer and its considerably lower price compared to the dextran used. Subsequently, the biopolymer solution was passed through an Ystral mixer (Ystral Gmbh, BallrechtenDottingen, Germany) (16,000 rpm and 3 min) and a microfluidizer (M110L Microfluidics, Newton, MA, USA) 3 times at 9,000 psi. Citrem and fish oil were added slowly, under nitrogen atmosphere, into the resulting biopolymer solution during mixing at 17,500 rpm using an Ultraturrax T-25 homogenenizer (IKA, Staufen, Germany). The fish oil was added during the first 5 min of mixing, and the total mixing time was 8 min. The resulting electrospraying solutions contained $20 \mathrm{wt}$ \% fish oil (with respect to biopolymer). Samples were used immediately after production for electrospraying.

\subsection{Electrospraying process}

Electrospraying of the biopolymer solutions containing emulsified fish oil and antioxidants was carried out by using the patent pending Fluidnatek ${ }^{\mathrm{TM}}$ LE500 Capsultek pilot equipment (Bioinicia S.L., Valencia, Spain) as described in our previous study [17]. The Fluidnatek ${ }^{\mathrm{TM}}$ LE500 Capsultek equipment is assisted by pressurized air, which leads to a high-throughput electrospraying process. Solutions were processed using a flowrate of $1.8 \mathrm{~mL} / \mathrm{min}$ and $15 \mathrm{kV}$. The collection of the encapsulated powder was carried out in a grounded cyclonic collector as a free flowing powder. Temperature was maintained at $24{ }^{\circ} \mathrm{C}$ and relative humidity at $40 \%$. The production batches had a duration of $40 \mathrm{~min}$.

\subsection{Physicochemical properties of electrosprayed capsules}

\subsubsection{Morphology}

The morphology of the electrosprayed capsules was determined by scanning electron microscopy (SEM) (Phenom Pro, Phenom-World B.V., Eindhoven, the Netherlands). Approximately $0.5 \times 0.5 \mathrm{~cm}$ of the 
capsules aluminium sheet was placed on carbon tape and sputter coated with gold, $8 \mathrm{~s}, 40 \mathrm{~mA}$ utilizing

a Q150T Quorum Coater (Quorum Technologies Ltd, East Sussex, UK). The capsule diameter distribution

was determined by using the program ImageJ (National Institutes of Health). One hundred random capsules were measured.

\subsubsection{Oil distribution}

The fish oil-loaded electrosprayed capsules were re-dispersed in distilled water. For that purpose, $1 \mathrm{~g}$ of

capsules was dissolved in $15 \mathrm{~mL}$ of distilled water at room temperature under magnetic stirring (100 rpm) for 30 min and the resulting dispersion was filtered. Then, the droplet size distribution was measured by laser diffraction in a Mastersizer 2000 (Malvern Instruments, Ltd., Worcestershire, UK). Solutions were diluted in recirculating water (3000 rpm), until it reached an obscuration of $12 \%$. The refractive indices of sunflower oil (1.469) and water (1.330) were used as particle and dispersant, respectively. Results were given in surface area mean diameter $\left(\mathrm{D}_{3,2}\right)$ and $90 \%$ percentile ( $\left.\mathrm{d}_{0.9}\right)$. Measurements were made in triplicate.

\subsubsection{Encapsulation efficiency}

Encapsulation efficiency (EE) was determined by measuring the non-encapsulated oil, as described by Westergaard (2004) with some modifications. In brief, $1 \mathrm{~g}$ of electrosprayed capsules was immersed in $5 \mathrm{~mL}$ heptane and stirred at $100 \mathrm{rpm}$ for $2 \mathrm{~min}$. Then, the suspension was filtered and the retained solid washed three times with $2 \mathrm{~mL}$ heptane. From the recovered liquid, the heptane was evaporated and the amount of extracted oil was weighed. Analyses were carried out in triplicate. Results are expressed in wt.\% of the oil encapsulated mass against the total oil content of the capsules.

\subsubsection{Oxidative stability}

The storage experiment was carried out at $20^{\circ} \mathrm{C}$ in the dark for 21 days. Approximately, $2.2 \mathrm{~g}$ of capsules were stored in a $10 \mathrm{~mL}$ vial in order to maintain a similar headspace. Each vial contained the amount of sample required for peroxide value and volatiles analysis at each day of storage. Samples were taken at days $0,3,8,14$ and 21 for analysis. Storage time was selected according to our previous study [17]. 
2.4.4.1 Determination of peroxide value $(P V)$

Oil was extracted from approximately $0.5 \mathrm{~g}$ of capsules according to Bligh and Dyer method using a reduced amount of the chloroform/methanol (1:1, wt.\%) solvent [20]. Two extractions were made from each sample. PV was determined on lipid extracts using the colorimetric ferric-thiocyanate method at $500 \mathrm{~nm}$ as described by Shantha and Decker (1994). Results were expressed as miliequivalents of peroxides per kg of oil.

\subsubsection{Volatiles secondary oxidation products}

The volatiles secondary oxidation products were determined by dynamic headspace GC-MS. Approximately, $0.4 \mathrm{~g}$ of capsules and $10 \mathrm{mg}$ internal standard (4-methyl-1-pentanol, $30 \mu \mathrm{g} / \mathrm{g}$ water) were weighed out in a $100 \mathrm{~mL}$ purge bottle, to which $5 \mathrm{~mL}$ of distilled water and $1 \mathrm{~mL}$ antifoam (Synperonic $800 \mu \mathrm{L} / \mathrm{L}$ water) were added. The bottle was heated to $45^{\circ} \mathrm{C}$ in a water bath while purging with nitrogen (flow rate $250 \mathrm{~mL} / \mathrm{min}, 30 \mathrm{~min}$ ). Volatile secondary oxidation products were trapped on Tenax GR tubes. The volatiles were desorbed again by heating $\left(200^{\circ} \mathrm{C}\right)$ in an Automatic Thermal Desorber (ATD-400, Perkin Elmer, Norwalk, CN), cryofocused on a cold trap $\left(-30^{\circ} \mathrm{C}\right)$, released again $\left(220^{\circ} \mathrm{C}\right)$, and led to a gas chromatograph (HP 5890IIA, Hewlett Packard, Palo Alto, CA, USA; Column: DB-1701, $30 \mathrm{~m} \times 0.25 \mathrm{~mm} \times 1.0 \mu \mathrm{m}$; J\&W Scientific, CA, USA). The oven program had an initial temperature of $45^{\circ} \mathrm{C}$ for $5 \mathrm{~min}$, increasing at $1.5^{\circ} \mathrm{C} / \mathrm{min}$ until $55^{\circ} \mathrm{C}$, at $2.5^{\circ} \mathrm{C} / \mathrm{min}$ until $90^{\circ} \mathrm{C}$, and at $12.0^{\circ} \mathrm{C} / \mathrm{min}$ until $220^{\circ} \mathrm{C}$, where the temperature was kept for $4 \mathrm{~min}$. The individual compounds were analysed by mass-spectrometry (HP 5972 mass-selective detector, Agilent Technologies, USA; electron ionization mode, $70 \mathrm{eV}$; mass to charge ratio scan between 30 and 250). The individual compounds were identified by both MS-library searches (Wiley 138 K, John Wiley and Sons, Hewlett-Packard) and by authentic external standard and quantified through calibration curves. The external standards employed were 2-ethyl-furan, 1-penten-3-one, pentanal, 1-penten-3-ol, $(E)$-2-pentenal, hexanal, $(E)$-2hexenal, heptanal, 2-pentyl-furan, (E,E)-2,4-heptadienal and nonanal (Sigma-Aldrich, Brøndby, Denmark). Samples were analyzed in triplicate. 


\subsection{Production of capsule-enriched mayonnaise}

Light-mayonnaise (40 wt.\% of total oil) was enriched with fish oil (2.5 wt.\%) by using three different approaches: i) neat fish oil, ii) fish oil-loaded glucose syrup capsules without antioxidants, and iii) fish oil-loaded glucose syrup capsules with commercial antioxidants (500 ppm $\delta$-tocopherol and 500 ppm rosemary extract, with respect to fish oil). The mayonnaise batches of $120 \mathrm{~g}$ were prepared using a Turbo blender (Moulinex, Lyon, France). Each batch contained by weight 37.5\% rapeseed oil, 2.5\% fish oil, 4\% egg yolk, $0.4 \%$ lemon juice, $0.3 \%$ salt, $1 \%$ vinegar, 0.5 Grindsted FF and $0.1 \%$ potassium sorbate. The batch with neat fish oil also contained 1\% sugar and 52.7\% water; whereas no sugar was added to the mayonnaise batches with electrosprayed capsules, which contained $43.7 \%$ water plus the other ingredients present in the capsules $(0.3 \%$ whey protein, $0.3 \%$ citrem, $2 \%$ pullulan and $7.5 \%$ glucose syrup). Egg yolk powder, potassium sorbate, salt and sugar were mixed into the water for $15 \mathrm{~s}$. The two oils (rapeseed and fish oil) were mixed together and a small portion was taken to dissolve the Grindsted

FF before this was added to the water mixture. The mixture was blended for another $15 \mathrm{~s}$. To the remaining oil, lemon juice and vinegar were added. The oil mixture was then slowly poured (30 s) into the blender to form an emulsion. At this stage, the capsules were added and mixed with the mayonnaise for $60 \mathrm{~s}$. Finally, the material from the wall of the mixer was poured down and the whole mayonnaise mixed together for $15 \mathrm{~s}$.

Mayonnaises (15 g) were stored in $50 \mathrm{~mL}$ brown bottles at $25^{\circ} \mathrm{C}$ for 28 days in the dark [14, 15]. Samples were taken at 5 different time points (day 0, 7, 14, 21 and 28) and subdivided into two brown bottles (6 and 9 g, respectively), flushed with $\mathrm{N}_{2}$ and stored at $-40{ }^{\circ} \mathrm{C}$ until PV and volatiles analyses were performed. Droplet size and viscosity measurements were performed in fresh mayonnaise samples at days 0 and 28.

\subsection{Characterization of capsules-enriched mayonnaise}

\subsubsection{Droplet size and viscosity}

The droplet size distribution of the mayonnaise samples was measured by laser diffraction (Matersizer 2000, Malvern Instruments Ltd., Worcestershire, UK). Previously, mayonnaise was dissolved in SDS 
buffer (10 mM NaH2 $\mathrm{PO}_{4}, \mathrm{pH}$ 7) at a ratio of 1:5 (w/w) and sonicated for $15 \mathrm{~min}$. This analysis was carried out in duplicate. Results are given in weighted volume mean diameter ( $\left.\mathrm{D}_{4,3}\right)$.

The viscosity of the mayonnaise samples was determined at $25^{\circ} \mathrm{C}$ by using a Stresstech ${ }^{\circledR} \mathrm{HR}$ (Reologica Instruments, Lund, Sweden) with both upper and lower plate serrated (P30 serrated). The instrument was operated at $2 \mathrm{~mm}$ gap with increased stress from 5-65 Pa in 30 logarithmic steps. This analysis was performed in duplicate.

\subsubsection{Oxidative stability}

The determination of PV was carried out as described in section 2.4.4.1 by extracting the oil from semithawed mayonnaise samples.

The measurement of the volatiles secondary oxidation products was performed as described in section

2.4.4.2 with some modifications. Approximately, $3 \mathrm{~g}$ of mayonnaise and $30 \mathrm{mg}$ internal standard (4methyl-1-pentanol, $30 \mu \mathrm{g} / \mathrm{g}$ water) were weighed out in a $100 \mathrm{~mL}$ purge bottle, to which $5 \mathrm{~mL}$ of distilled water and $1 \mathrm{~mL}$ antifoam (Synperonic $800 \mu \mathrm{L} / \mathrm{L}$ water) were added. The bottle was heated to $60^{\circ} \mathrm{C}$ in a water bath while purging with nitrogen (flow $150 \mathrm{~mL} / \mathrm{min}, 30 \mathrm{~min}$ ). Volatile secondary oxidation products were trapped on Tenax GR tubes. Volatile acids were removed by $0.1 \mathrm{~g} \mathrm{KOH}$ during the headspace collection by using an S-tube with $\mathrm{KOH}$. The volatiles were desorbed in the gas chromatograph as described above. The temperature programme was as follows: 3 min at $35{ }^{\circ} \mathrm{C}, 3$ ${ }^{\circ} \mathrm{C} / \mathrm{min}$ from 35 to $120^{\circ} \mathrm{C}, 7^{\circ} \mathrm{C} / \mathrm{min}$ to $120-160{ }^{\circ} \mathrm{C}, 15^{\circ} \mathrm{C} / \mathrm{min} 160-200{ }^{\circ} \mathrm{C}$ and hold for 4 min at 200

${ }^{\circ} \mathrm{C}$. The individual volatiles were analysed by MS, identified by both library and external standards and quantified through calibration curves as indicated above. Results were expressed in ng/g of mayonnaise.

\subsection{Statistical analysis}

Statgraphics 18 (Statistical Graphics Corp., Rockville, MD, USA) was used for data analysis. Data were expressed as mean \pm standard deviation. Firstly, multiple sample comparison analysis was performed to identify significant differences between samples. Secondly, mean values were compared by using the Tukey's test. Differences between means were considered significant at $\mathrm{p}<0.05$. 


\section{Results and discussion}

\subsection{Physicochemical properties of electrosprayed capsules}

\subsubsection{Morphology, encapsulation efficiency and oil distribution}

Fish oil-loaded electrosprayed capsules with spherical shape were obtained for both types of biopolymers (dextran and glucose syrup). Dextran capsules presented a smoother surface than glucose syrup capsules, which showed more holes on the surface and some capsules-agglomerates (Fig. 1). This is similar to our previous study [17] and also indicates that the addition of antioxidants to fish oil-loaded electrosprayed capsules did not influence capsule morphology. Furthermore, dextran capsules presented a lower diameter than both types of glucose syrup capsules (e.g. with seaweed or commercial antioxidants). Approximately $80 \%$ of dextran capsules were below $2 \mu \mathrm{m}$, whereas $80 \%$ of glucose syrup capsules were below $3 \mu \mathrm{m}$ (Fig. 1). This is in agreement with the lower $\mathrm{D}_{0,9}$ values of re-suspended dextran capsules when compared to glucose capsules containing seaweed antioxidants (D-SW and GSW, respectively) (Table 1). Smaller oil droplet size has been reported to lead to spray-dried capsules with smaller diameters [22]. However, this cannot explain the differences observed between D-SW capsules and glucose syrup capsules with commercial antioxidants (G-COM), with the latter showing a lower $\mathrm{D}_{0,9}$ value but larger capsule diameter (Table 1). This suggests that differences in capsule diameter are more influenced by the type and concentration of biopolymers used than the oil droplet size (measured in this study as re-suspended capsules). Glucose syrup solution had a high content of pullulan (4 wt.\%) compared to dextran solution (1 wt.\%), which may have affected the formation of capsules agglomerates and larger capsules through more pullulan chain entanglements.

Similarly, the results of oil droplet size distribution obtained for the re-suspended capsules were not aligned with the EE values (Table 1). For instance, G-SW re-suspended capsules, having a significantly higher $\mathrm{D}_{0,9}$ value, presented a significantly higher EE value than G-COM. In this regard, previous studies have reported that coalescence of the extractable oil after reconstitution of the nano-microcapsules could occur, indicating that results should be carefully interpreted [23]. In any case, significantly higher EE was observed for D-SW than for G-SW and G-COM capsules, which correlates well with the smoother 
surface and lower amount of holes for dextran capsules. These results are in line with our previous study

[17] where fish oil-loaded glucose syrup capsules without antioxidants showed holes on the surface

(attributed to the presence of non-encapsulated oil droplets), had significantly lower EE than fish oil-

loaded dextran capsules (without antioxidants).

\subsubsection{Oxidative stability}

Fig. 2 shows the content of primary oxidation products of the capsules stabilized with antioxidants during storage. It was observed that the capsules had a PV of 5-12 meq/kg oil after production, with a lag phase of approximately 8 days. After this period, the PV of the capsules increased considerably, with final PV varying from $20.0 \pm 4.5$ to $34.6 \pm 0.5 \mathrm{meq} / \mathrm{kg}$ oil (Fig. 2). When comparing these results with our previous study where capsules without antioxidants were evaluated [17], we observed that the addition of natural antioxidants (either seaweed or commercial antioxidants) did not decrease the PV of the capsules during storage. On the contrary, a prooxidant effect of the seaweed extract was found when added to glucose syrup capsules, leading to a significantly higher PV at 21 days of storage (34.6 \pm 0.5 meq/kg oil) when compared to glucose syrup capsules without antioxidants (19.7 $\pm 4.4 \mathrm{meq} / \mathrm{kg}$ oil) [17].

The same prooxidant effect was observed for this type of capsules regarding the formation of some secondary volatiles oxidation products such as 1-penten-3-ol (which derives from the oxidation of omega-3 fatty acids) and nonanal (which derives from the oxidation of omega-9 fatty acids) (Fig. 3). This is attributed to the co-extraction of other substances like pigments and metals present in $F$. vesiculosus which can act as prooxidants [24]. Particularly, the ethanol extract used in this study contained $14.5 \pm 0.1 \mu \mathrm{g}$ iron/g dry extract, which may potentially catalyse lipid oxidation in the form of metal ions [15]. Nonetheless, it is noteworthy that the same seaweed extract exhibited an antioxidant effect in the dextran capsules, as observed for all volatiles shown in Fig. 3 except for 1-penten-3-ol. A plausible explanation is that the metal ions present in the seaweed extract can catalyse oxidation to a larger extent in G-SW than in D-SW capsules due to the significantly lower EE value of G-SW (Table 1). This implies a larger amount of unprotected oil in G-SW, which can be easily oxidized by the action of the free metal ions, resulting in a prooxidative effect far stronger than the antioxidant activity of the 
phlorotannins. Another possibility is that phlorotannins were differently distributed in the capsules due to a different interaction with dextran and glucose syrup. Dextran, which has surface activity, could have favorably interacted with phlorotannins leading to their location close to the interface between oil droplets and wall material. However, this needs further research in order to be confirmed.

On the other hand, the addition of commercial antioxidants ( $\delta$-tocopherol combined with rosemary extract) to glucose syrup capsules (G-COM) led to a significantly lower concentration of volatiles compounds (apart from 1-penten-3-ol) when compared to G-SW capsules (Fig. 3). Furthermore, when comparing with our previous results on glucose syrup capsules without antioxidants [17], a significant decrease in the formation of some volatiles such as $(E)$-2-pentenal (derived from oxidation of omega-3 fatty acids) and nonanal were found for G-COM capsules. This is in line with the improvement previously reported on the oxidative stability of omega-3 loaded-pullulan fibers when stabilized with $\delta$ tocopherol and rosemary extract [7], which is attributed to the combined effect of lipophilic radical scavengers (e.g. $\delta$-tocopherol) and synergistic compounds (e.g. carnosic acid present in the rosemary extract) [25].

G-COM and D-SW capsules showed similar oxidative stability with no significant differences in their volatile content at the last sampling point, except for nonanal (Fig. 3). The significantly higher formation of nonanal in G-COM capsules is explained by the high content of pullulan in these capsules, since nonanal has been detected in high concentration in pullulan nanofibers that did not contain fish oil [7].

\subsection{Physicochemical properties of capsules-fortified mayonnaise}

Electrosprayed capsules produced with glucose syrup, which is a cheap biopopolymer already used in food applications, were selected for enrichment of mayonnaise. Particularly, the effect of using omega3 loaded-electrosprayed glucose capsules without antioxidants or with commercial natural antioxidants on the physical and oxidative stability of the enriched mayonnaise was evaluated and compared with the use of neat fish oil. 


\subsubsection{Physical stability}

The physical stability of the mayonnaise samples was assayed by measuring droplet size distribution and viscosity during storage. Significant differences were observed for the droplet size distribution of the mayonnaise samples after production. The mayonnaise enriched with neat fish oil (M_oil) showed a significantly smaller droplet size, which was followed by the mayonnaise enriched with glucose syrup capsules without antioxidants (M_G) and with commercial antioxidants (M_G-COM) (Fig. 4a).

Moreover, although the mayonnaises did not show creaming during storage, droplet size after 28 days storage increased significantly in capsule-containing mayonnaises (which was not observed for M_oil)

(Fig. 4a). These findings indicated that adding glucose syrup capsules to an already formed mayonnaise and blending for $60 \mathrm{~s}$ could have led to: i) flocculation/coalescence of existing oil droplets, and/or ii) disintegration of the capsules structure resulting in non-encapsulated oil droplets that could have flocculated and coalescence. Similarly, previous studies on fish oil-enriched mayonnaise reported both physical stability and destabilization during storage. For instance, Sørensen et al. [26] reported no changes in the droplet size of light mayonnaises containing only rapeseed oil during storage, but the authors observed an increase in droplet size when replacing part of the rapeseed oil with neat fish oil while using both egg yolk and milk proteins as emulsifiers.

Fig. $4 \mathrm{~b}$ shows that the three types of mayonnaise had pseudoplastic behaviour. At low shear rate $\left(<1 \mathrm{~s}^{-}\right.$ ), the mayonnaises presented different apparent viscosities. For instance, capsule-containing mayonnaises (M_G and M_G-COM) showed a higher apparent viscosity when compared to mayonnaise enriched with neat fish oil (M_oil). This was expected since electrosprayed capsules were constituted of $80 \%$ biopolymers, thus capsule-containing mayonnaises had a lower water content compared to M_oil. Moreover, the biopolymers used (e.g. pullulan, dextran or glucose syrup) may have acted as thickeners if the capsules desintegrated, increasing the viscosity of the aqueous phase. It has to be mentioned that the viscosity of the three type of mayonnaises slightly decreased after 28 days of storage (Fig. 4b). This correlates well with the larger oil droplet size observed for M_G and M_G-COM after storage, which led to less friction between droplets as a consequence of a reduced surface-to-volume ratio of the dispersed phase [27]. 


\subsubsection{Oxidative stability}

Fig. 5 shows the development of primary oxidation products in fish oil enriched mayonnaises during 28 days of storage. The mayonnaise samples presented a low initial PV ranging from 0.2 to $0.5 \mathrm{meq} / \mathrm{kg}$ oil. A lag phase of 7 days was observed for capsule-containing mayonnaises, whereas mayonnaise enriched with neat fish oil had a longer lag phase (up to 14 days). It was found that mayonnaise enriched with neat fish oil had a significantly $(p<0.05)$ lower PV (Fig. 5) and content of volatile secondary oxidation products (Fig. 6) throughout storage compared with capsule-containing mayonnaise. This may be attributed to a potential disintegration of the structure of the capsules when added to the mayonnaise, resulting in the release of unprotected fish oil which is highly susceptible to oxidation. It may also explain the lower oxidative stability of the capsule-containing mayonnaises because of the release of fish oil with poorer oxidative status (when compared to neat fish oil) due to the oxidation suffered during the production of the capsules (as shown in Fig. 2 and Fig. 3). It should be noted that the addition of commercial natural antioxidants to the capsules neither reduced the formation of primary oxidation products in the enriched mayonnaise (Fig. 5) nor the formation of secondary volatile oxidation products (Fig. 6). Surprisingly, M_G-COM was found to have significantly $(p<0.05)$ higher PV and higher content of $(E)-2-p e n t e n a l$ than M_G at the end of the storage. These findings indicate that although the addition of $\delta$-tocopherol and rosemary extract reduced lipid oxidation in fish oil-loaded electrosprayed capsules during storage, they did not have the same protective effect when the capsules where added to a water-based food matrix like mayonnaise. On the other hand, it is noteworthy that oxidation in egg yolk-based mayonnaise is highly metal-catalysed due to the release of iron bounded to the protein phosvitin at low pH (e.g. pH 4) (Jacobsen, Timm, \& Meyer, 2001). Hence, antioxidants with metal chelating properties are necessary to prevent lipid oxidation in mayonnaise. However, $\delta$-tocopherol and rosemary extract rich in carnosic acid and carnosol are chain breaking antioxidants with radical scavenging activity, but poor metal chelating activity [29]. Hence, this may be the reason why these antioxidants did not reduce lipid oxidation in fish oil-enriched mayonnaise in case that the capsules were dissolved in the aqueous phase of the mayonnaise. Likewise, previous studies have shown the 
importance of metal chelators in the protection of long chain omega-3 PUFA in mayonnaise and that tocopherols only showed poor antioxidant activity in mayonnaise fortified with neat fish oil [28, 30].

\section{Conclusions}

The addition of antioxidants to fish-oil loaded electrosprayed capsules neither modified the size distribution of the capsules nor the EE. Dextran capsules containing the seaweed extract had an

improved oxidative stability in terms of volatiles oxidation products such as $(E)$-2-pentenal, heptanal and nonanal. On the other hand, the seaweed extract had a prooxidant effect in glucose syrup capsules, which was attributed to a more severe interaction of metal ions with non-encapsulated oil and to a potential different distribution of phlorotannins in the capsules. The potential different interaction of dextran and glucose syrup with phlorotannins, which may have affected their distribution in the capsules, needs further investigation. The addition of $\delta$-tocopherol and rosemary extract enhanced the oxidative stability of the glucose syrup capsules during storage. $\delta$-Tocopherol, which is lipophilic, would preferably locate in the oil droplet, which seems to be beneficial to prevent lipid oxidation in electrosprayed capsules when combined with synergestic antixiodants (e.g. carnosic acid and carnosol) from the rosemary extract.

Capsule-containing mayonnaise had larger droplet size and higher apparent viscosity than mayonnaise enriched with neat fish oil, although they were stable against creaming during one month of storage. However, the enrichment of mayonnaise with encapsulated fish oil resulted in lower oxidative stability both when using electrosprayed capsules without or with $\delta$-tocopherol and rosemary extract. This may be explained by the release of non-encapsulated fish oil in the mayonnaise with a poorer oxidative status. Therefore, the intactness of the fish oil-loaded glucose syrup capsules needs to be further investigated in order to confirm their structure when added to a water-based food matrix such as mayonnaise. Moreover, the use of hydrophobic wall materials (e.g. zein), which could facilitate to keep the structure of electrosprayed-capsule in mayonnaise deserves further study. 


\section{Acknowledgements}

This work was supported by the European Commission (ELECTRONANOMEGA project). P.J. García-

Moreno acknowledges a Marie-Curie postdoctoral fellowship (Grant Agreement 654818).

\section{References}

[1] F. Shahidi, J Funct Food. 2015, 19, 797

[2] A. P. Bimbo, in Food Enrichment with Omega-3 Fatty Acids, (Eds: A.D.-M. Sørensen, N. S. Nielsen, A. F. Horn, C. Jacobsen), Elsevier, New York, 2013, Ch. 2.

[3] E. N. Frankel, Lipid oxidation, Oily Press, 2005.

[4] M. B. Let, C. Jacobsen, and A. S. Meyer, J. Agric. Food Chem., 2007, 55, 7802

[5] P. J. García-Moreno, N. Özdemir, K. Stephansen, R. V. Mateiu, Y. Echegoyen, J. M. Lagaron, I. S. Chronakis, and C. Jacobsen, Food Hydrocoll., 2017, 69, 273

[6] C. Jacobsen, P. J. García-Moreno, A. C. Mendes, R. V. Mateiu, and I. S. Chronakis, Annu. Rev. Food Sci. Technol., 2018, 9, 525

[7] P. J. García-Moreno, C. Damberg, I. S. Chronakis, and C. Jacobsen, Eur. J. Lipid Sci. Technol., 2017, 119, 1600305

[8] R. C. Lindenschmidt, A. F. Tryka, M. E. Goad, and H. P. Witschi, Toxicology, 1986, 38, 151

[9] C. Jacobsen, M. B. Let, N. S. Nielsen, and A. S. Meyer, Trends Food Sci. Technol., 2008, 19, 76

[10] J. Xie, P. VanAlstyne, A. Uhlir, and X. Yang, Eur. J. Lipid Sci. Technol., 2017, 119, 1600439

[11] I. D. Chkhikvishvili and Z. M. Ramazanov, Appl. Biochem. Microbiol., 2000, 36, 289

[12] T. Wang, R. Jónsdóttir, H. Liu, L. Gu, H. G. Kristinsson, S. Raghavan, and G. Ólafsdóttir, J. Agric. Food Chem., 2012, 60, 5874

[13] T. Wang, R. Jónsdóttir, and G. Ólafsdóttir, Food Chem., 2009, 116, 240

[14] D. B. Hermund, B. Yeşiltaş, P. Honold, R. Jónsdóttir, H. G. Kristinsson, and C. Jacobsen, J. Funct. Foods, 2015, 19, 828

[15] P. J. Honold, C. Jacobsen, R. Jónsdóttir, H. G. Kristinsson, and D. B. Hermund, Eur. Food Res. 
Technol., 2015, 242, 571

[16] D. B. Hermund, A. Karadağ, U. Andersen, R. Jónsdóttir, H. G. Kristinsson, C. Alasalvar, and C. Jacobsen, J. Agric. Food Chem., 2016, 64, 8359

[17] P. J. García-Moreno, A. Pelayo, S. Yu, M. Busolo, J. M. Lagaron, I. S. Chronakis, and C. Jacobsen, J. Food Eng., 2018, 231, 42

[18] A. Karadağ, D. B. Hermund, L. H. S. Jensen, U. Andersen, R. Jónsdóttir, H. G. Kristinsson, C. Alasalvar, and C. Jacobsen, Eur. J. Lipid Sci. Technol., 2017, 119, 1500578

[19] V. Westergaard, Niro A/S, 2004.

[20] E. G. Bligh and W. J. Dyer, Can. J. Biochem. Physiol., 1959, 37, 911

[21] N. C. Shantha and E. A. Decker, J. AOAC Int., 1994, 77, 421

[22] S. Ramakrishnan, M. Ferrando, L. Aceña-Muñoz, S. De Lamo-Castellví, and C. Güell, Food Bioprocess Technol., 2013, 6, 3088

[23] S. Drusch and S. Berg, Food Chem., 2008, 109, 17

[24] S. L. Holdt and S. Kraan, J. Appl. Phycol., 2011, 23, 543

[25] Y. Serfert, S. Drusch, and K. Schwarz, Food Chem., 2009, 113, 1106

[26] A.-D. M. Sørensen, N. S. Nielsen, G. Hyldig, and C. Jacobsen, Eur. J. Lipid Sci. Technol., 2010, 112, 1012

[27] R. Pal, AIChE J., 1996, 42, 3181

[28] C. Jacobsen, M. Timm, and A. Meyer, J. Agric. Food Chem., 2001, 49, 3947

[29] S. Drusch, N. Groß, and K. Schwarz, Eur. J. Lipid Sci. Technol., 2008, 110, 351

[30] C. Jacobsen, K. Hartvigsen, P. Lund, J. Adler-Nissen, G. Hølmer, A. Meyer, Eur. Food Res. Technol., 2000, 210, 242

[31] C. Jacobsen, K. Hartvigsen, P. Lund, M. K. Thomsen, L. H. Skibsted, G. Hølmer, J. Adler-Nissen, and A. S. Meyer, Eur. Food Res. Technol., 2001, 212, 308 


\section{Tables}

Table 1. Oil droplet size of redispersed nano-microcapsules and encapsulation efficiency
Electrosprayed capsules
\begin{tabular}{cc}
\multicolumn{2}{c}{ Oil droplet size, $\mu \mathrm{m}$} \\
\hline $\mathrm{D}_{3,2}$ & $\mathrm{D}_{0,9}$
\end{tabular}
Encapsulation efficiency (EE), \%

\begin{tabular}{cccc}
\hline D-SW & $0.458 \pm 0.073^{\mathrm{a}}$ & $2.687 \pm 0.735^{\mathrm{a}}$ & $90.4 \pm 0.1^{\mathrm{a}}$ \\
G-SW & $0.465 \pm 0.038^{\mathrm{a}}$ & $4.592 \pm 0.826^{\mathrm{b}}$ & $85.7 \pm 0.4^{\mathrm{b}}$ \\
G-COM & $0.632 \pm 0.100^{\mathrm{a}}$ & $2.181 \pm 0.119^{\mathrm{c}}$ & $83.2 \pm 0.5^{\mathrm{c}}$ \\
\hline
\end{tabular}

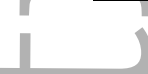

D-SW: dextran capsules with seaweed antioxidants; G-SW: glucose syrup capsules with seaweed antioxidants; G-COM: glucose syrup capsules with commercial antioxidants.

Letters $(a-c)$ indicate statistical significant differences $(p<0.05)$ between samples. 


\section{Figures}
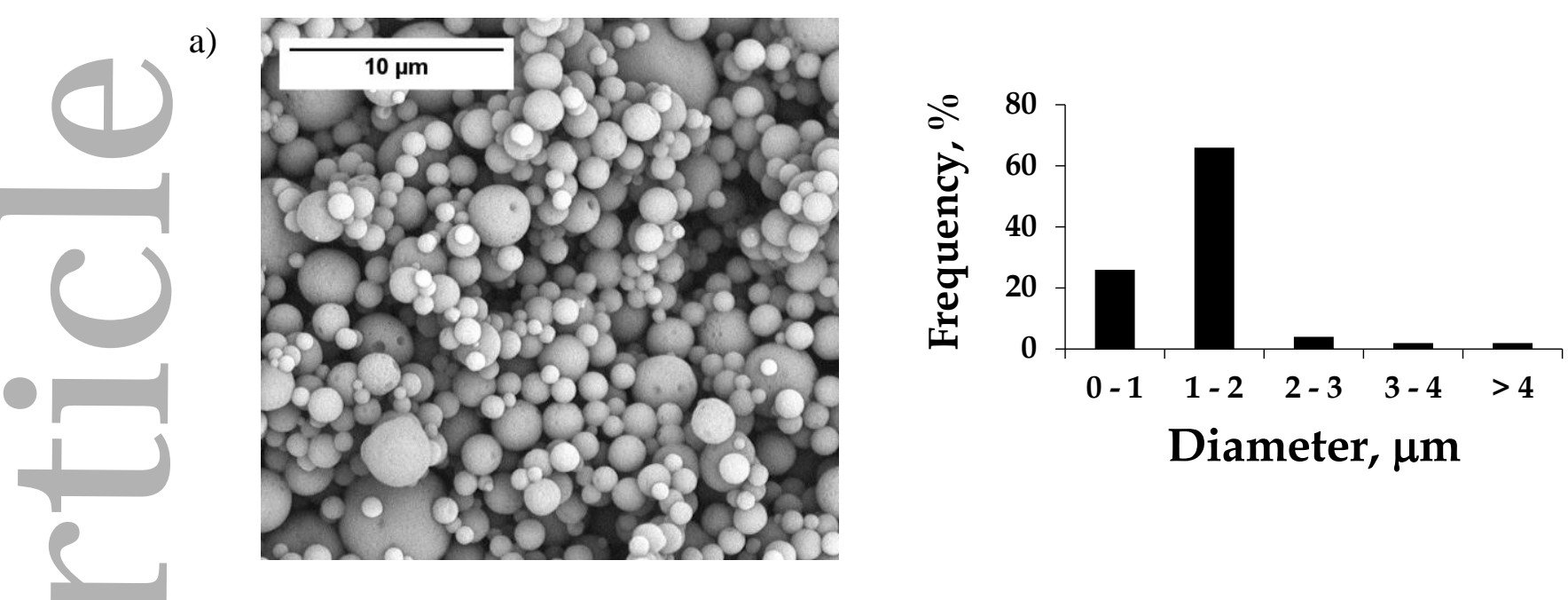

b)
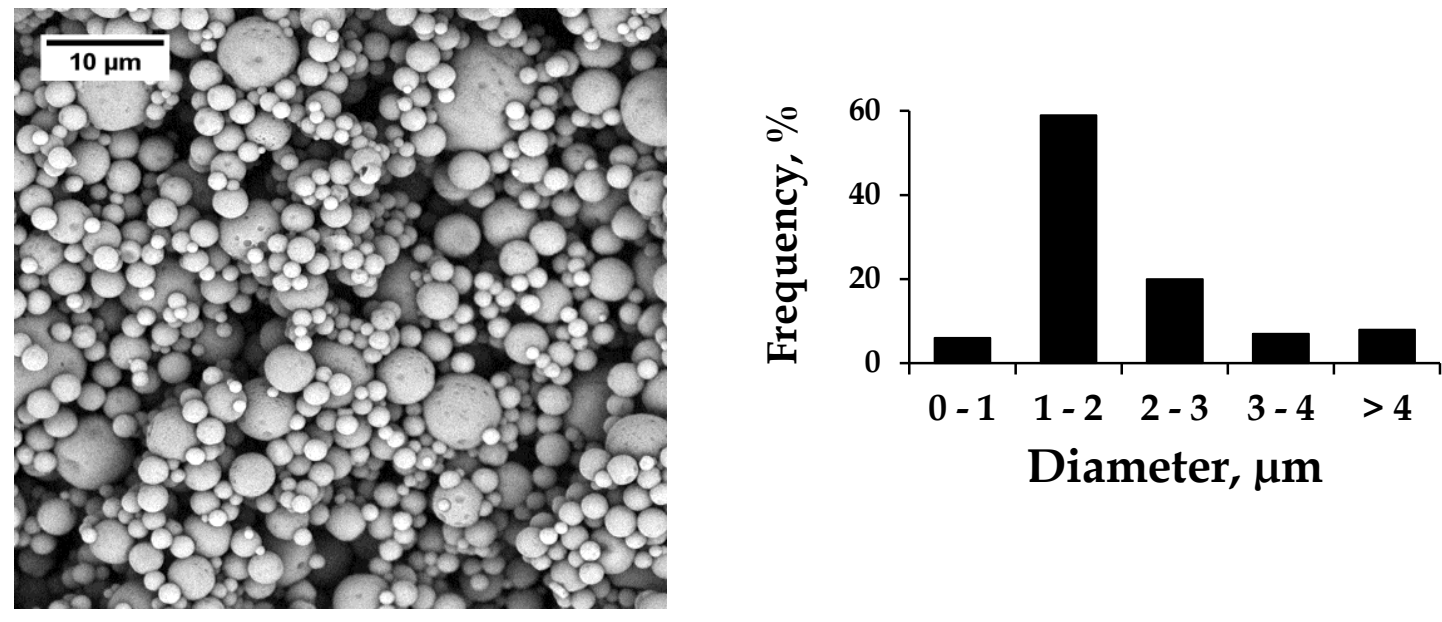

c)
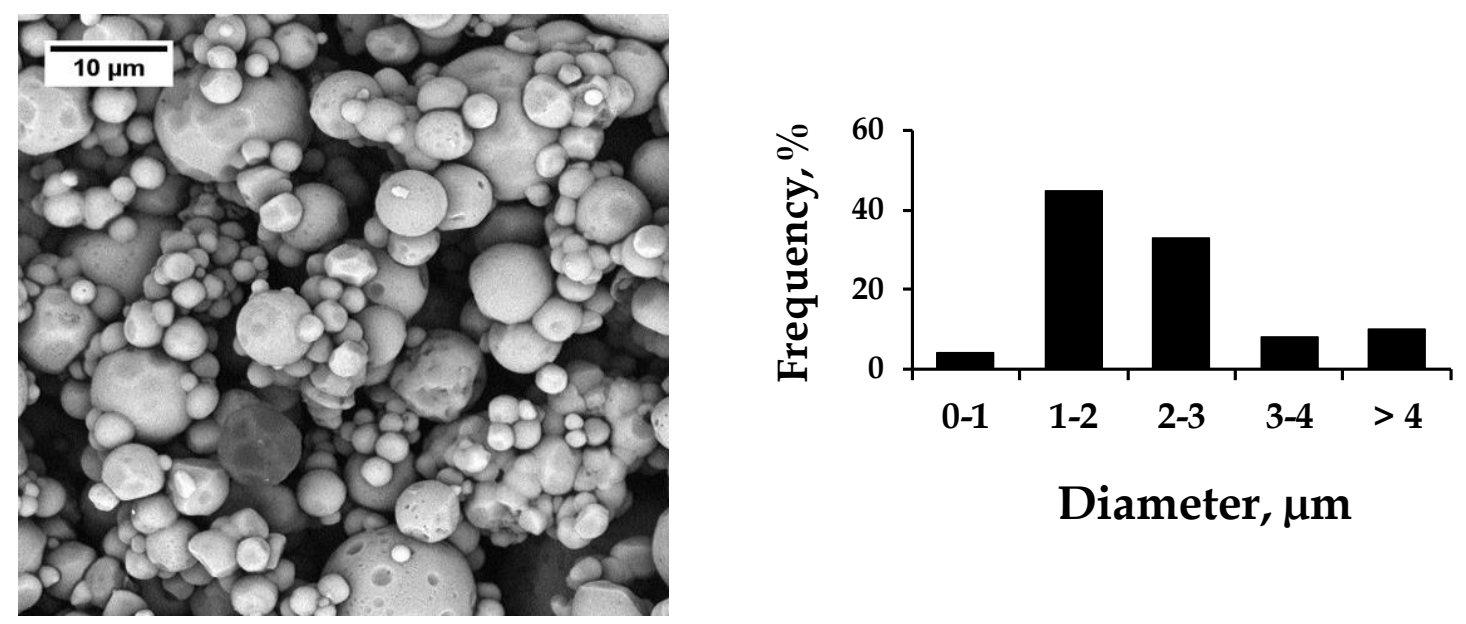

Figure 1. SEM images and diameter distribution of fish oil-loaded electrosprayed capsules stabilized with antioxidants: a) D-SW, dextran capsules with seaweed antioxidants, b) G-SW, glucose syrup capsules with seaweed antioxidants, and c) G-COM, glucose syrup capsules with commercial antioxidants. 


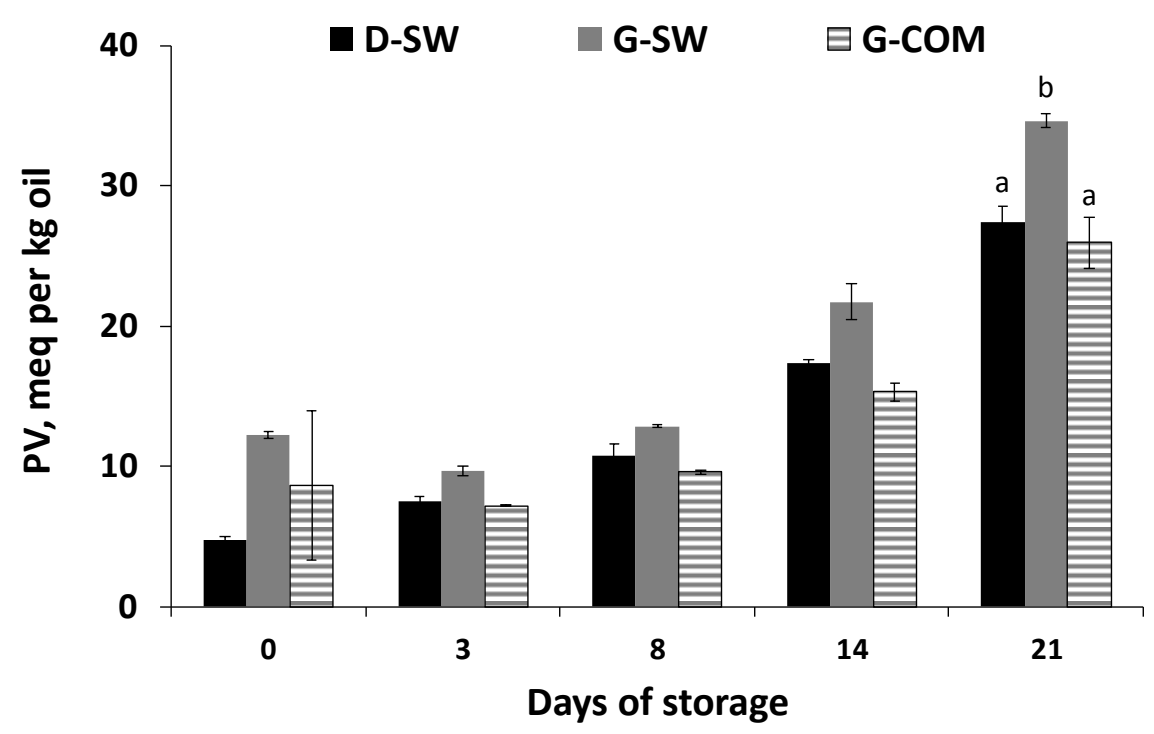

Figure 2. Peroxide value (PV) of electrosprayed capsules loaded with fish oil and stabilized with antioxidants during storage at $20^{\circ} \mathrm{C}$.

D-SW: dextran capsules with seaweed antioxidants; G-SW: glucose syrup capsules with seaweed antioxidants; G-COM: glucose syrup capsules with commercial antioxidants.

Letters $(a-b)$ indicate statistical significant differences $(p<0.05)$ between capsule samples at day 21 . 
a)

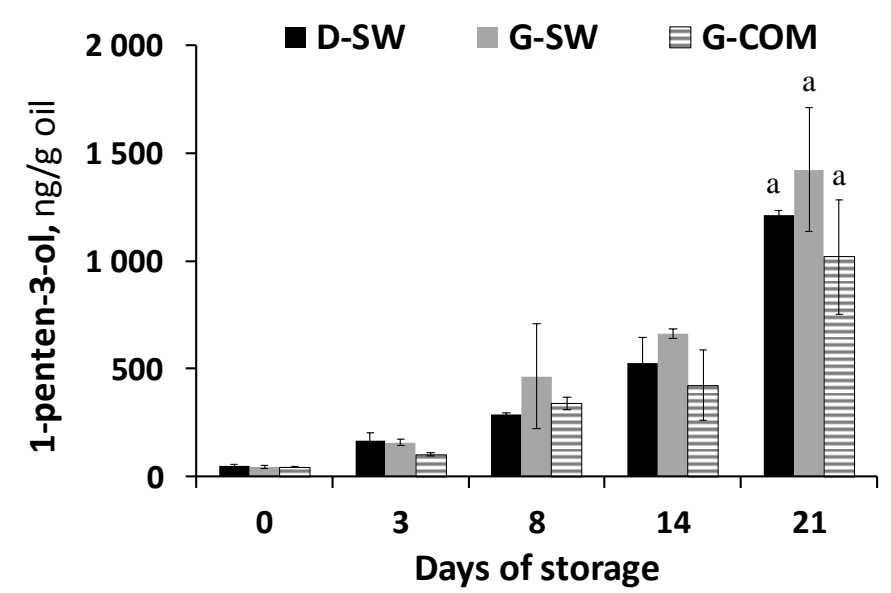

c)

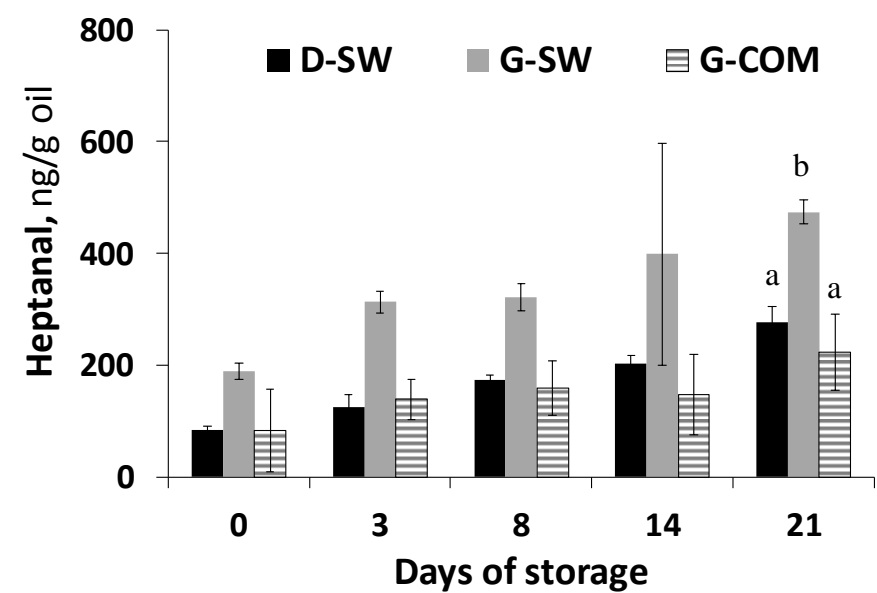

b)

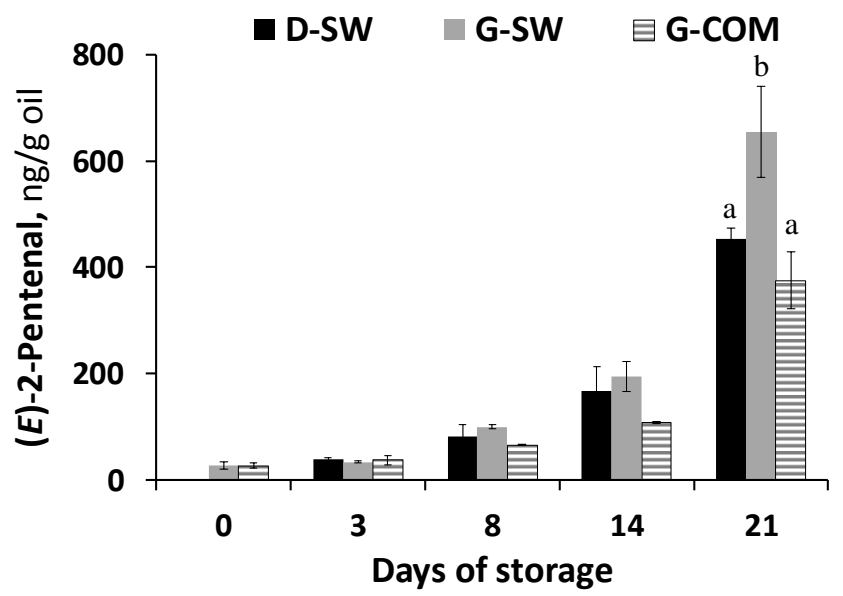

d)

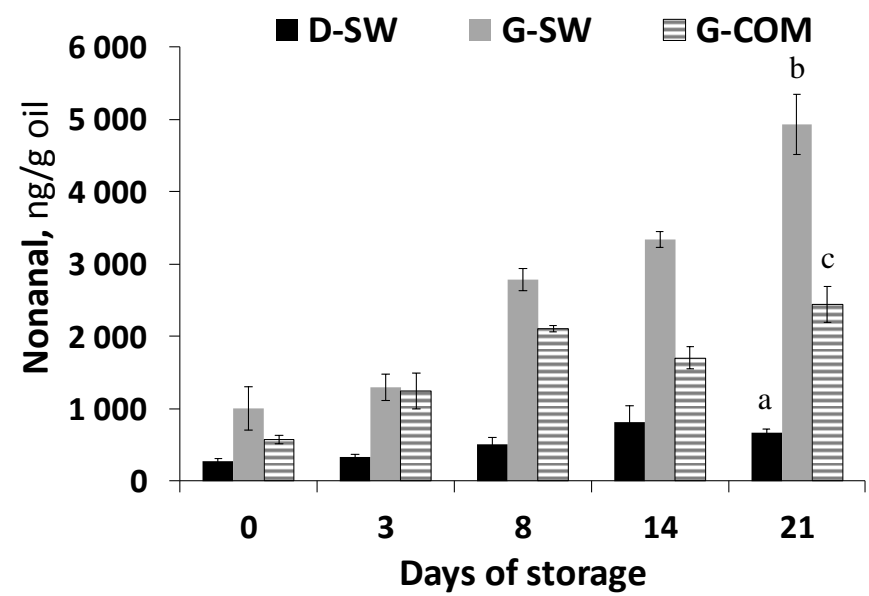

Figure 3. Secondary volatile oxidation products of electrosprayed capsules loaded with fish oil and stabilized with antioxidants during storage at $20{ }^{\circ} \mathrm{C}$ : a) 1-penten-3-ol, b) (E)-2-pentenal, c) heptanal, d) nonanal.

D-SW: dextran capsules with seaweed antioxidants; G-SW: glucose syrup capsules with seaweed antioxidants; G-COM: glucose syrup capsules with commercial antioxidants. Letters $(a-c)$ indicate statistical significant differences $(p<0.05)$ between capsule samples at day 21.

To make it easier for the reader to compare the results, the concentration of volatiles in fish oil-loaded capsules with dextran and glucose syrup capsules as main biopolymers respectively, after 21 day storage at $20^{\circ} \mathrm{C}$ [17], are shown here: 1 -penten-3-ol, $1161 \pm 222$ and $751 \pm 70 \mathrm{ng} / \mathrm{g}$ oil; (E)-2-pentenal, $585 \pm 23$ and $606 \pm 1 \mathrm{ng} / \mathrm{g}$ oil; heptanal, $430 \pm 54$ and $357 \pm 83 \mathrm{ng} / \mathrm{g}$ oil; nonanal, $666 \pm 57$ and $3831 \pm 267 \mathrm{ng} / \mathrm{g}$ oil. 
a)

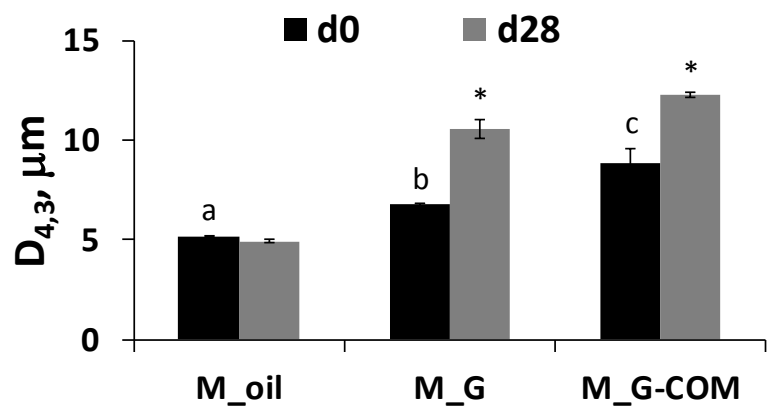

b)

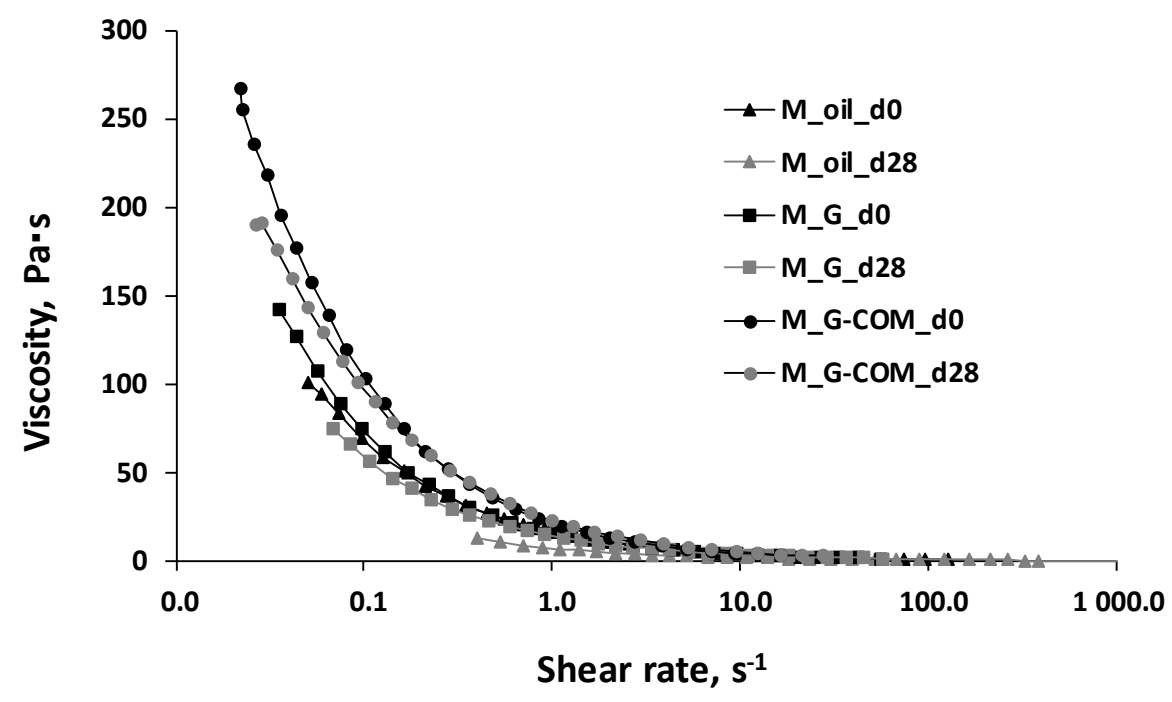

Figure 4. Physical stability of the mayonnaise samples during storage at $25{ }^{\circ} \mathrm{C}$ for 28 days: a) droplet size, and b) viscosity.

M_oil: mayonnaise fortified with neat fish oil; M_G: mayonnaise fortified with glucose syrup capsules without antioxidants; M_G-COM: mayonnaise fortified with glucose syrup capsules with commercial antioxidants.

Letters $(a-c)$ indicate statistical significant differences $(p<0.05)$ between mayonnaise samples at day 0 .

* indicates significant differences $(p<0.05)$ for a mayonnaise sample between days 0 and 28. 


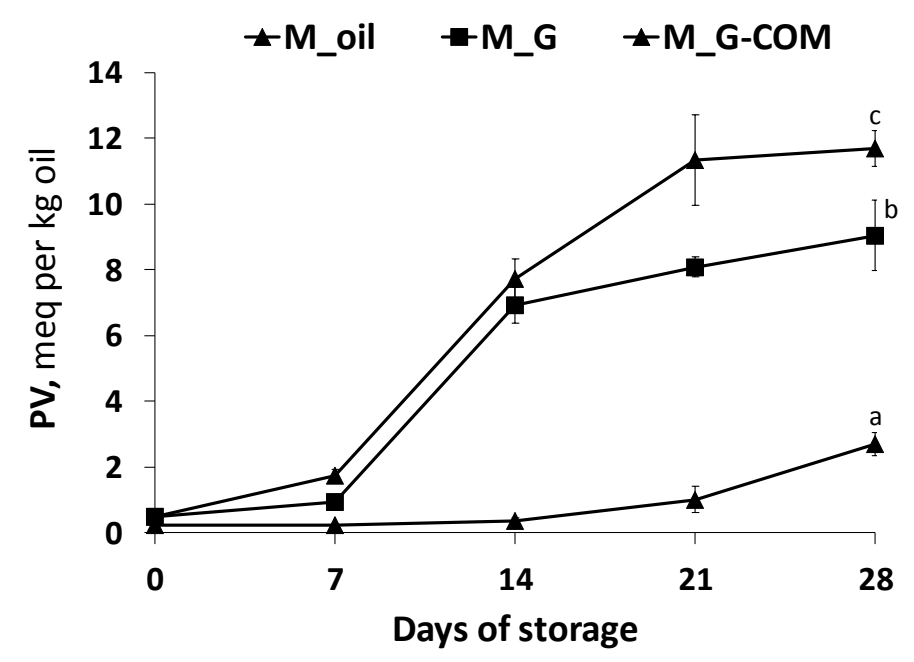

Figure 5. Peroxide value (PV) of mayonnaise samples during storage at $25{ }^{\circ} \mathrm{C}$.

M_oil: mayonnaise fortified with neat fish oil; M_G: mayonnaise fortified with glucose syrup capsules without antioxidants; M_G-COM: mayonnaise fortified with glucose syrup capsules with commercial antioxidants.

Letters $(a-c)$ indicate statistical significant differences $(p<0.05)$ between mayonnaise samples at day 28. 
a)

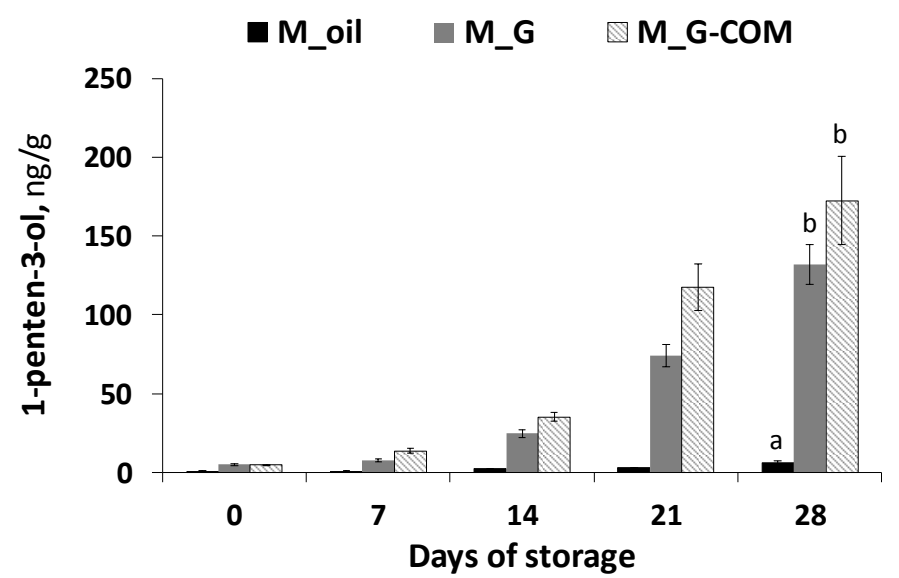

c)

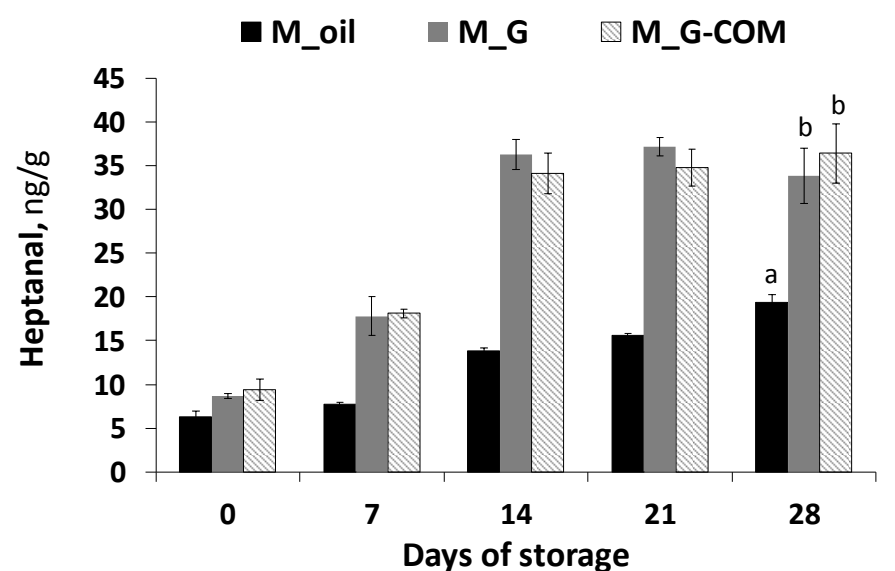

b)

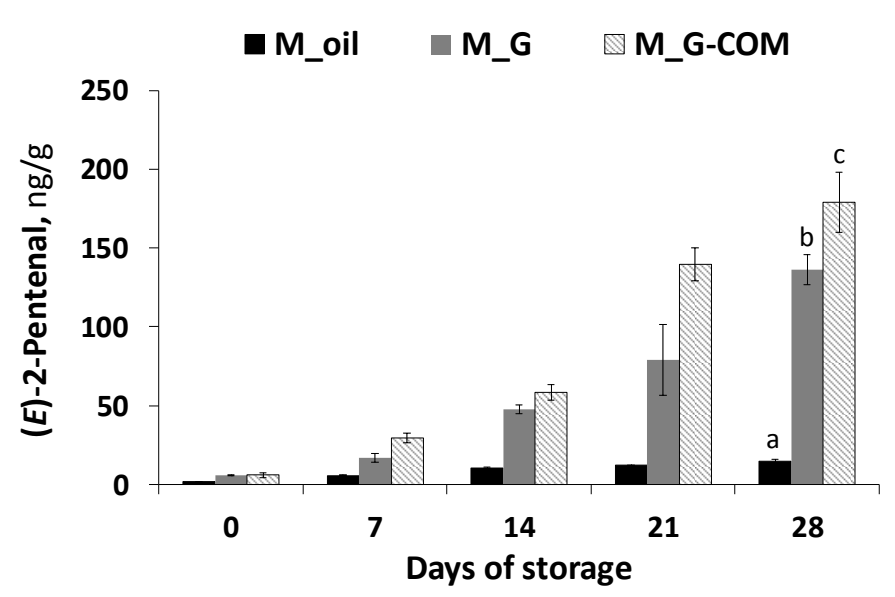

d)

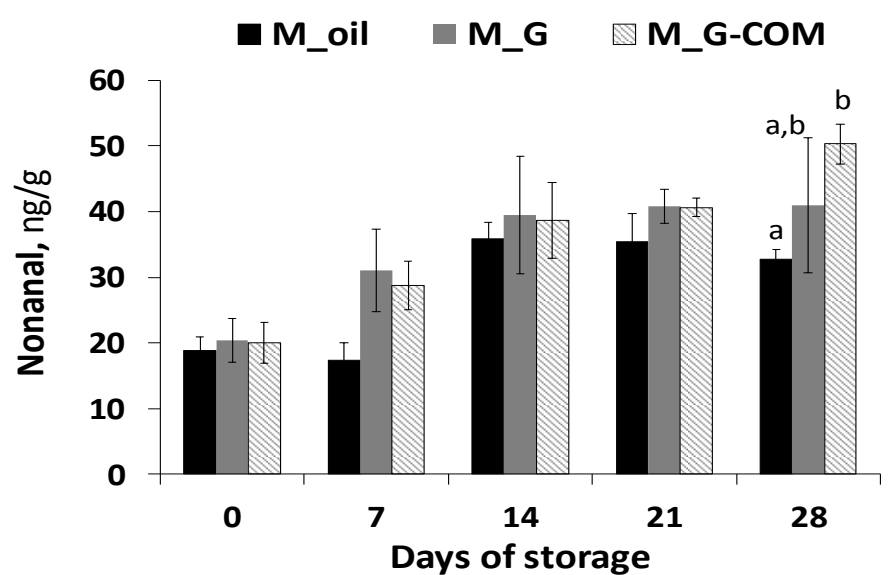

Figure 6. Secondary volatile oxidation products of mayonnaise samples during storage at $25^{\circ} \mathrm{C}$ : a) 1-penten-3-ol, b) (E)-2-pentenal, c) heptanal, d) nonanal.

M oil: mayonnaise fortified with neat fish oil; M G: mayonnaise fortified with glucose syrup capsules without antioxidants; M G-COM: mayonnaise fortified with glucose syrup capsules with commercial antioxidants.

Letters $(a-c)$ indicate statistical significant differences $(p<0.05)$ between mayonnaise samples at day 28 